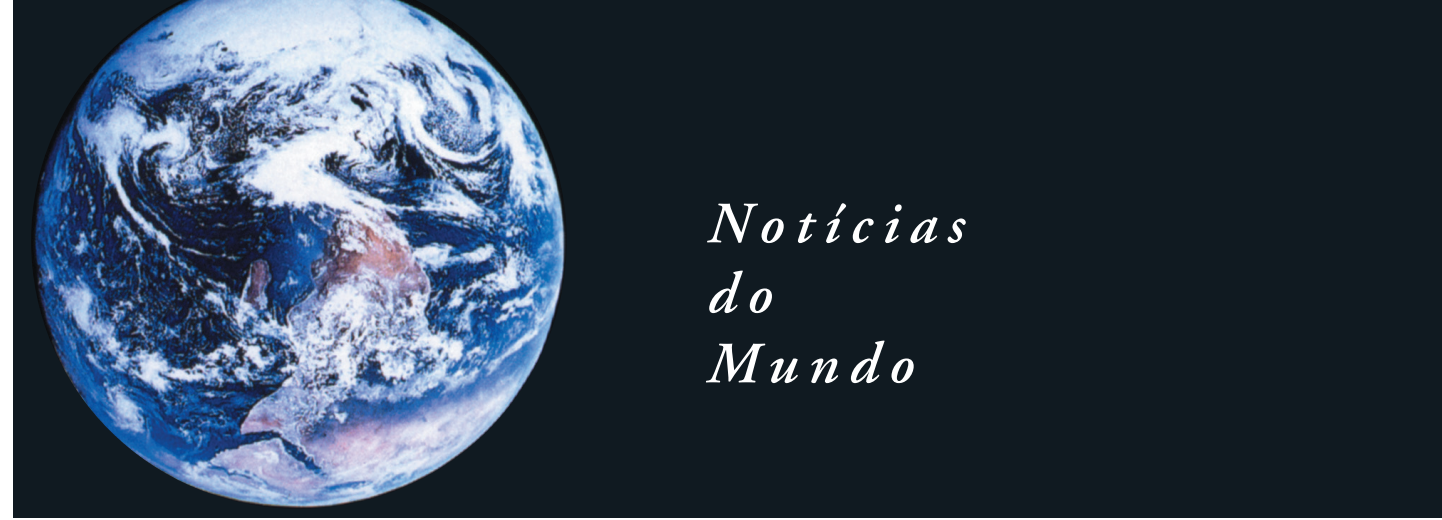

ENTREVISTA: Elizabeth RaseKoAla

\title{
Fundadora da Rede da África e do Caribe para a Ciência e a Tecnologia (ACNST)
}

A Rede da África e do Caribe para a Ciência e a Tecnologia (ACNST) é uma ONG criada em 1995, na Cidade do Cabo, África do Sul, pela engenheira química nigeriana Elizabeth Rasekoala. O trabalho da rede é promover o desenvolvimento do capital humano; discutir questões de raça e igualdade de gênero e incentivar a inclusão social no empreendimento científico. "Eu diria que o trabalho da rede teve um impacto profundo, com mudanças reais", afirma Elizabeth". A fundadora da ACNST é uma das palestrantes da $13^{a}$ Conferência Internacional de Comunicação Pública da Ciência e Tecnologia (PCST), realizada de 5 a 8 de maio em Salvador, Bahia. Ela debaterá sobre o principal tema do evento: comunicação pública da ciência para inclusão social e engajamento político. Nesta entrevista, Rasekoala fala sobre os principais desafios do desenvolvimento científico no continente africano e sobre as mudanças que ocorreram desde que a ACNST foi criada.

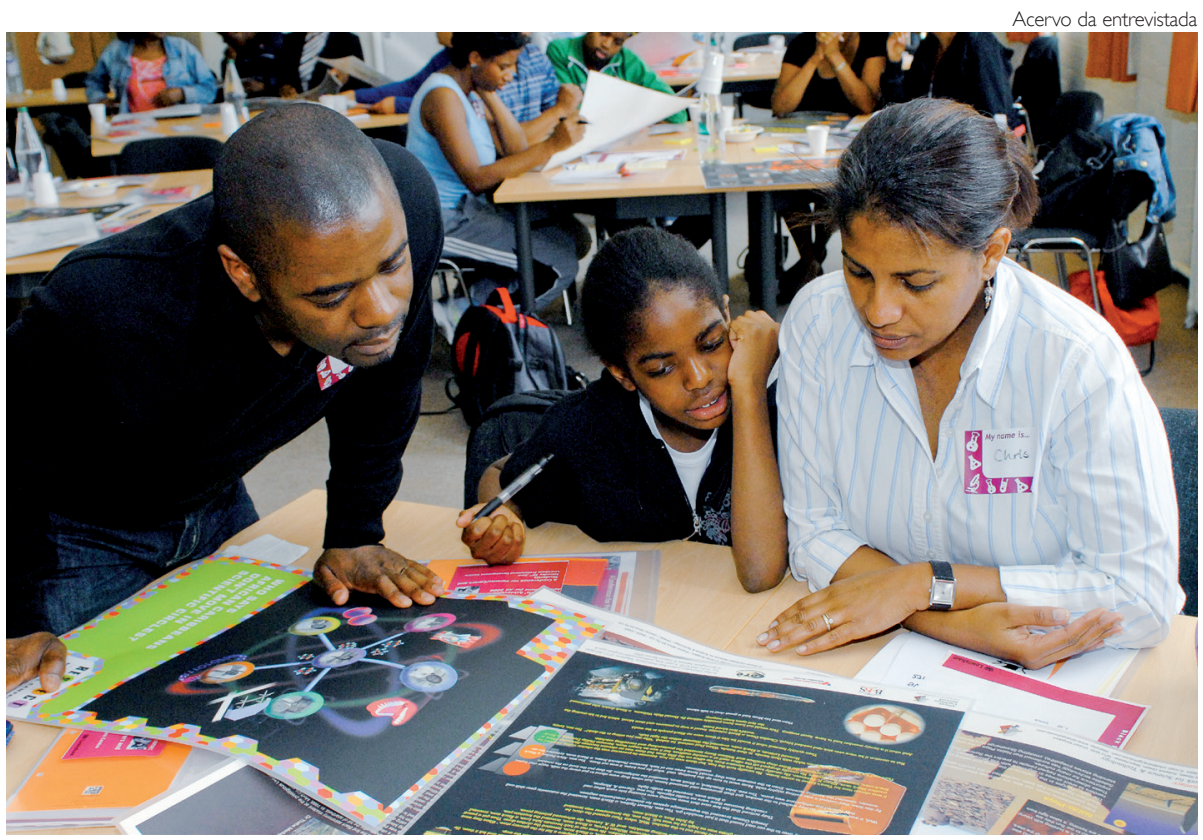

Trabalho da rede ampliou participação feminina nas ciências

Ciência e Cultura: Quais são os principais desafios para o desenvolvimento científico no continente africano?

Elizabeth Rasekoala: $\mathrm{O}$ primeiro grande desafio é a vontade política. Isso se aplica a todos os países africanos. Nossos políticos parecem não entender que a ciência tem papel fundamental para o desenvolvimento. Isso é uma grande frustração. $\mathrm{O}$ segundo problemaéo financiamento para ciência e para pesquisa. Há mais de vinte anos, todos os países africanos se comprometeram, no âmbito do Plano de Ação de Lagos, em gastar pelo menos $1 \%$ de seu PIB em pesquisa científica. Até agora, apenas cinco países atingiram esse objetivo:
Egito, Marrocos, Tunísia, Maurício e Ruanda, único país que não só atingiu como excedeu esse objetivo. Hoje, Ruanda emprega 3\% do PIB em pesquisa científica e o governo se comprometeu a ampliar essa porcentagem para $5 \%$ até o fim desta década. Nossos institutos de pesquisa científica dependem de financiamento estrangeiro. Então, a realidade é que as necessidades de desenvolvimento do continente não são atendidas. $\mathrm{O}$ tipo de pesquisa que se faz na África é totalmente desconectado da realidade da vida das pessoas comuns, o que nos leva ao terceiro desafio: essa desconexão significa que a mentalidade científica não está incorporada na cultura da maioria do nosso povo. 


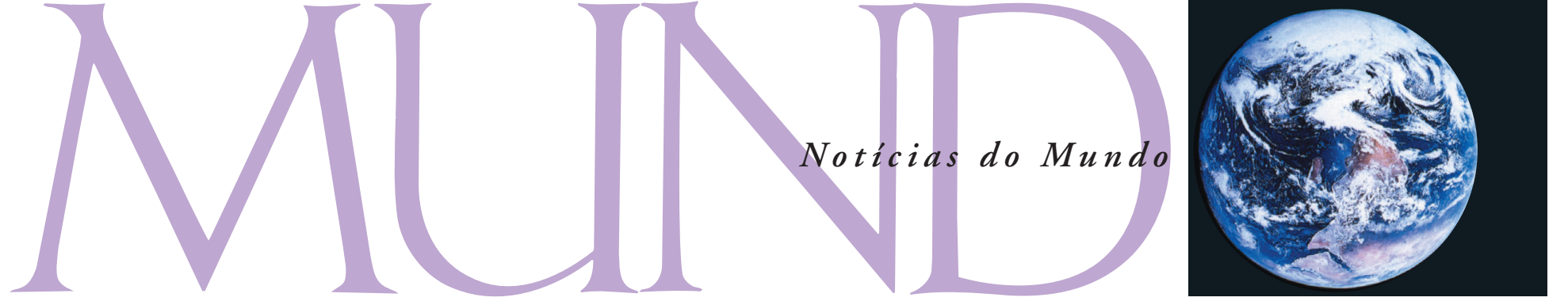

A ciência continua sendo praticada por uma elite. Isso é um problema grande. O quarto desafio é o desenvolvimento de capital humano, de encontrar maneiras de ampliar a força de trabalho científica a partir do nível escolar até a universidade e os institutos de pesquisa. Acabamos perdendo o capital humano limitado que somos capazes de formar através da "fuga de cérebros". As pessoas se qualificam, fazem doutorado e vão para o exterior porque não há oportunidades no continente. Nós continuamos nesse ciclo vicioso. Eu diria que esses quatro principais desafios se aplicam a todos os 54 países do continente.

Como é possível tornar a ciência importante para o debate público e inclusão social nos países em desenvolvimento em que a população sofre com a falta de condições básicas de sobrevivência?

Não se trata apenas de sobrevivência. Precisamos de um debate público sobre ciência que realmente permita à maioria da população estabelecer a relação entre a vacinação e as doenças infantis, como pólio, sarampo e o impacto na mortalidade infantil, algo que faça mulheres entenderem a ligação entre planejamento familiar, contracepção e o impacto no índice de mortalidade materna, um dos principais indicadores de desenvolvimento. Um dos consensos sobre o continente africano é que a falta de inclusão social é a causa principal de conflitos. A ciência pode auxiliar a inclusão social nesses países o que evitaria vários conflitos.

Você afirmou que a ACNST foi criada porque havia uma grande preocupação com a sub-representação de pessoas negras em ciência, engenharia e tecnologia. O que mudou de 1995 até hoje?

Antes de a rede começar, essa questão era ocultada no Reino Unido e na Europa. Todos conheciam a situação, mas ninguém queria comentar. O que nós fizemos foi mostrar que autoridades do setor educacional e dos governos escondiam dados que demonstravam essa segregação. A partir desses dados, mudamos o discurso para que a questão da segregação por raça e gênero fosse integrada às discussóes sobre o sistema de ciência e tecnologia. Foi uma luta que levou cinco anos, mas chegamos lá. Hoje, o governo é responsável pela coleta de dados em níveis escolares e nas universidades para mostrar as realizaçôes por gênero e raça em matemática e ciência. Também conseguimos mudanças na formação de professores, além da elaboração de materiais culturalmente apropriados de aperfeiçoamento em matemática e ciência, alguns desses produzidos por autoridades do setor educacional. Finalmente, conseguimos fazer o sistema científico aceitar que havia um problema e que era necessário mudar. Eu diria que o trabalho da rede realmente teve um impacto profundo. Foi uma batalha que alcançou mudanças reais.
Ainda existe muito preconceito em relação a questões de gênero. Como está a situação na África?

É um desafio em todos os países do continente. Alguns estão melhores que outros. O leste africano é uma região modelo em termos de gênero na ciência e tecnologia. Eles têm instituições bastante sólidas que ajudam a sustentar os avanços nesta questão. A região do oeste africano está bem, não por causa das instituições, mas por causa das dimensões culturais. Os Iorubas, por exemplo, tem uma cultura que realmente valoriza a mulher. $\mathrm{O}$ mesmo acontece com as mulheres Igbo. Acredito que, por isso, as pessoas acham que não existe uma necessidade de inserir as mulheres nos quadros das instituições. Não é verdade. Devemos olhar para o continente de maneira mais institucional para tratar questões de gênero em ciência e tecnologia. De modo geral, a parte boa é que nos níveis fundamental, médio e na universidade, a participação de garotas em temas relacionados a matemática e ciências está crescendo. A luta é para que as mulheres também façam mestrado e doutorado e se insiram no mercado de trabalho. É na pós-graduação que mais perdemos mulheres, o que é realmente uma pena, pois não temos um modelo para convencer as meninas mais jovens de que elas podem ter uma carreira valiosa. 